\title{
New data reporting phthalates in delta of the Selenga River as the main tributary of Lake Baikal
}

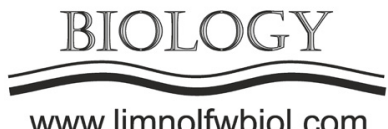

\author{
Radnaeva L.D.*, Taraskin V.V., Shiretorova V.G., Budaeva O.D. \\ Baikal Institute of Nature Management Siberian Branch of the Russian Academy of Sciences, Sakhyanovoy str., 6, Ulan-Ude, 670047, \\ Russia
}

\begin{abstract}
Phthalates are chemical compounds that have been widely used in industrial chemistry and national economy. They are classified as priority toxicants in the system of environmental monitoring of foreign countries. Phthalates are not chemically bonded to the polymer matrix, that is why they easily migrate to the environment during waste disposal of phthalate-containing products as a result of plastic aging and decomposition. Getting into the environment phthalates inevitably accumulate in human bodies and animals, causing disruption of the endocrine system. For the first time 6 priority phthalates were studied in the surface water of the main channels of the Selenga River's delta in winter low-water period. Benzyl butyl phthalate (BBP), dibutylphthalate (DBP) and bis(2-ethylhexyl) phthalate (DEHP) were found in the highest content. Di-octyl phthalate (DOP) was not detected.
\end{abstract}

Keywords: estuary of the Selenga River, water, phthalates

\section{Introduction}

One of the global environmental issues is the pollution of ecosystems with phthalic acid derivatives - phthalates. Multimillion productions of phthalates (over 7 million tons per year) for the manufacture of plastics, paints and varnishes, etc., increasing consumption of such materials, and the lack of proper methods for their disposal along with the high migrating ability of the phthalic acid derivatives are causing concern of scientists all over the world. Such phthalates as dimethyl phthalate (DMF), diethyl phthalate (DEP), di-n-butyl phthalate (DBP), benzyl butyl phthalate (BBP), bis (2-ethylhexyl) phthalate (DEHP) and di-n-octyl phthalate (DOP) are recognized by the United States Environmental Protection Agency (US EPA) as endocrine disrupting chemicals and are classified as a priority pollutant (Zheng et al., 2014). The metabolism products and disruption of phthalates under environmental conditions are more toxic than initial substances (IARC monographs..., 2000; Benjamin et al., 2013).

The issue of phthalate's content in the objects within the Baikal Natural Territory has been studied at different times by the scientists from LIN SB RAS (Baram et al., 2000; Azarova, 2003). The research made twenty years ago was mainly concerned with the studying of DEHP in the water area of Lake Baikal and the Selenga River in the section from Ulan-Ude till the delta. In recent studies Gorshkov A.G. and the authors discovered the spatial inequality of the distribution of
DBP (0.06-3.1 $\mu \mathrm{g} / \mathrm{L}$ ) and DEHP (0.03-1.4 $\mu \mathrm{g} / \mathrm{L}$ ) in the upper and deep aquafers of all Lake basins during the studying of phthalates in the pelagic zone and the coastal zone of Lake Baikal (Gorshkov et al., 2017). The content of investigated substances did not exceed the MPCs established in Russia for different types of water bodies. Nevertheless, taking into account the ever-increasing environmental impact on aquatic ecosystems from urbanized territories, the Lake's water content cyclicity, the issues related with the sources of phthalates and their volumes, which are brought in by the main drains of the Lake, remain important and unresolved. The presence of other phthalates (except DBP and DEHP) in aquatic ecosystems of the Baikal basin has not been studied yet. There is no systemic monitoring of this class of pollutants in Russia. Thus, the aim of this work was to determine DMF, DEP, DBP, BBP, DEHP and DOP in the surface waters of the main channels of the Selenga River's delta, as one of the indicators of the ecological state of Lake Baikal.

\section{Material and methods}

The objects of the research were surface water samples collected during the winter low water period at the end of February 2020, in the Selenga River (Murzino) and in the main channels of the delta (Levoberezhnaya, Kharauz - the Southern group, Galutai, Srednyaya - the Middle group, Severnaya, Lobanovskaya - the Northern group of channels ). Through the largest channels 
(Levoberezhnaya, Kharauz and Lobanovskaya) under conditions of medium water content, up to $80 \%$ of the water flow has been passing in the spring-autumn period, and up to $99 \%$ - in winter. Small channels (Galutai, Srednyaya and Severnaya) mostly freeze in the upper river in winter (Sinyukovich et al., 2004). The methodology of the American Environmental Protection Agency was taken as the basis for the sample operation and analysis. Water samples were extracted according to the US EPA 3510C method. The obtained extracts were analyzed using gas chromatography-mass spectrometry on an Agilent 7890B gas chromatograph with a $7000 \mathrm{C}$ mass spectrometric detector, in the SIM mode (monitoring of the selected ion) according to the US EPA 8270D method with some modifications. Standards and individual phthalates were purchased from Sigma Aldrich (purity $\geq 98 \%$ ).

\section{Results}

DMF was found in water samples from the Galutai (0.01 $\mu \mathrm{g} / \mathrm{L})$ and Lobanovskaya (0.02 $\mu \mathrm{g} / \mathrm{L})$ channels. Diethyl phthalate was detected in three out of the seven water samples from the channels Levoberezhnaya (0.03 $\mu \mathrm{g} / \mathrm{L})$, Srednyaya (0.21 $\mu \mathrm{g} / \mathrm{L})$ and Lobanovskaya (0.01 $\mu \mathrm{g} / \mathrm{L})$. The content of DBP was registered higher than that of DMF and DEP, and reached the values of $33.16 \mu \mathrm{g} / \mathrm{L}$ (Srednyaya channel) and 3.77 (Levoberezhnaya channel) with a standardization of $200 \mu \mathrm{g} / \mathrm{L}$ (MPCq-b) and $1 \mu \mathrm{g} / \mathrm{L}$ (MPCrx). Nowadays there are no regulatory documents regulating the content of BBP. However, BBP's quantities (0.03 $47.49 \mu \mathrm{g} / \mathrm{L}$ ) found in five out of the seven samples make a determinative contribution to the total content of these substances. The concentration of DEHP found in samples "Levoberezhnaya" and "Lobanovskaya" was 0.13 and $1.04 \mu \mathrm{g} / \mathrm{L}$.

\section{Discussion}

DBP (36.93 $\mu \mathrm{g} / \mathrm{L})$ and $\operatorname{BBP}(61.86 \mu \mathrm{g} / \mathrm{L})$ made the largest contribution to the amount of phthalates. The content of the amount of phthalates in channels water can be set in following descending order: Galutai $>$ Srednyaya $>$ Levoberezhnaya $>$ Lobanovskaya $>$ Kharauz $\approx$ Severnaya. Such distribution may be associated with the peculiarities of the water runoff during the ice period, the intensity of water exchange and the location of the channels (settlements in neighborhood). The highest total phthalate's content was registered in the channels of the middle part of the Selenga delta, where the runoff during the winter low-water period is minimal. Thus, the Srednyaya channel almost completely freezes in winter, so due to the low water exchange, high values of the saprobity index, organic matter content and very low values of oxygen were observed (Sorokovikova et al., 2006). Such conditions can contribute to the accumulation of phthalates, as it is known that the concentration of phthalates, in particular DEP and DBP, positively correlates with the content of organic matter in water and bottom sediments (Tatarnikov et al., 2013; Hassanzadeh et al., 2014). The widest range of phthalates was found in the Levoberezhnaya and Lobanovskaya channels that are located on the southern and northern edges of the delta, where settlements are concentrated. The presence of phthalates during the ice period may be associated with a low rate of biodegradation due to low water temperature, as well as the input from groundwater, where they get from landfills in warm season. The absence of phthalates in the Severnaya and Kharauz channels may be associated with the distance from settlements and with good water exchange, which contributes to the biodegradation of phthalates. In addition, it is known that bacteria are the main factor that reduces the content of 65 phthalates in surface waters and bottom sediments (Thuren, 1986; Vethaak et al., 2005).

\section{Conclusions}

Thus, for the first time, the studying of 6 priority phthalates was conducted in surface waters of the Selenga River's channels. 5 phthalates were found (DOP was not detected), where DBP and BBP made the largest contribution to the amount of phthalates. The content of these substances can vary widely depending on the physicochemical and microbiological parameters of the waters; however, the final degradation products flowed in Lake Baikal. So it is quite dangerous for the ecosystem. Taking the above mentioned into consideration, it is necessary to develop a monitoring system of phthalates and their main metabolites in order to assess and predict the risks of pollution of aquatic ecosystems within Baikal Natural Territory and to find ways to minimize anthropogenic impact.

\section{Acknowledgements}

Research was carried out during within the framework of the State assignment of Baikal Institute of Nature Management of SB RAS and with partial financial support from the Ministry of Science and Higher Education of Russian Federation (project №2020-1902-01-071) and The Russian Foundation for Basic Research (Project no. 17-29-05085 ofi_m).

\section{References}

Azarova I.N. 2003. HPLC method for determining di (2-ethylhexyl)phthalate to study its behavior in the lake Baikal ecosystem. Cand. Sc. Dissertation, Institute of Physical Chemistry RAS, Moscow, Russia. (in Russian)

Baram G.I., Azarova I.N., Gorshkov A.G. et al. 2000. Determination of bis(2-ethylhexyl) phthalate in water by high-performance liquid chromatography with direct on-column preconcentration. Journal of Analytical Chemistry 55: 750-754. DOI: 10.1007/BF02757910

Benjamin S., Masai E., Kamimura N. et al. 2013. Phthalates impact human health: epidemiological evidences and plausible mechanism of action. Journal of Hazardous Materials 36: 88-96. DOI: 10.1016/j.jhazmat.2017.06.036

Gorshkov A.G., Babenko T.A., Kustova O.V. et al. 2017. Priority phthalates in the Lake Baikal pelagic zone and coastal 
area. Chemistry for Sustainable Development 25: 351-359. DOI: 10.15372/CSD20170403

Hassanzadeh N., Esmaili-Sari A., Khodabandeh S. et al. 2014. Occurrence and distribution of two phthalate esters in the sediments of the Anzali wetlands on the coast of the Caspian Sea (Iran). Marine Pollution Bulletin 89: 128-135. DOI: 10.1016/j.marpolbul.2014.10.017

Sinyukovich V.N., Zharikova N.G., Zharikov V.D. 2004 The Selenga River runoff in the delta. Geografiya i Prirodnyye Resursy [Geography and Natural Resources] 3: 64-69. (in Russian)

IARC monographs on the evaluation of carcinogenic risks to humans. Vol. 77. Some industrial chemicals. 2000. Lyon: International Agency for Research on Cancer.

Sorokovikova L.M., Popovskaya G.I., Sinyukovich V.N. et al. 2006. Water chemistry and phytoplankton in water bodies in the Selenga River's delta under ice cover. Water Resources 33: 321-328. DOI: 10.1134/S0097807806030092
Tatarnikov V.O., Korshenko A.N., Kochetkov A.I. 2013. Phthalates in bottom sediments of the Caspian Sea. In: V International Scientific and Practical Conference "Problems of Preserving the Caspian Ecosystem in the Conditions of Oil and Gas Fields Development", pp. 187-191.

Thuren A. 1986. Determination of phthalates in aquatic environments. Bulletin of Environmental Contamination \& Toxicology 36: 33-40. DOI: 10.1007/BF01623471

Vethaak A.D., Lahr J., Schrap S.M. et al. 2005. An integrated assessment of estrogenic contamination and biological effects in the aquatic environment of the Netherlands. Chemosphere 59: 511-524. DOI: 10.1016/j. chemosphere.2004.12.053

Zheng X., Zhang B.-T., Teng Y. 2014. Distribution of phthalate acid esters in lakes of Beijing and its relationship with anthropogenic activities. Science of the Total Environment 476-477: 107-113. DOI: 10.1016/j.scitotenv.2013.12.111 